\title{
Cross Infection with Gastro-intestinal Tract Parasites between Red panda (Ailurus fulgens Cuvier, 1825) and Livestocks in Community Forest of Ilam, Nepal
}

\author{
Sajan Shrestha, Mahendra Maharjan \\ Central Department of Zoology, Tribhuvan University, Kirtipur, Kathmandu, Nepal
}

*Corresponding Author: Mahendra Maharjan, Central Department of Zoology, Tribhuvan University, Kirtipur, Kathmandu, Nepal

\begin{abstract}
From the Ilam community forest total 55 faecal samples of Red Panda $(n=14)$ and livestocks $(n=$ 41) were collected to analyses the cross- transmission of GI parasites between Red Panda and livestocks and vice-versa. For the examination, direct fecal smear, concentration techniques were utilized to identify the ocyst, cyst, eggs and larvae of parasites in feces. All the samples were found positive either for protozoan or helminth parasites. The recorded protozoan parasites were Eimeria sp., Entamoeba $s p$, and Balantidium $s p$. with their prevalence $64.28 \%, 57.14 \%$ and $14.28 \%$ respectively in Red Panda and $60.97 \%, 21.95 \%$ and $7.31 \%$ respectively in livestocks. In case of helmith parasites, seven nematode were recorded in Red Panda with different prevalence rate, Oxyuris (100\%), Ascaris (57.14\%), Trichostrongylus (50\%), Strongyloides $(50 \%)$, Trichuris (42.8\%), Crenosoma (42.85\%) and Hook Worm (35.7\%) but trematode and cestode were absent while in livestock six nematode Oxyuris (87.8\%), Ascaris (60.97\%), Strongyloids (53.65\%), Trichostrongylus (41.465), Hook Worm (39.02\%) and Trichuris (31.70\%) and one each of trematode and cestode: Paramphiostomum sp. $2.43 \%$ and Moniezia sp. $14.63 \%$ respectively. There was no statistical significant difference in prevalence of gastrointestinal parasites between Red Panda and livestocks $(P>0.05)$ which could be attributed to sharing of same pastures land. So, grazing system of livestock in the habitat of Red Panda should be stop.
\end{abstract}

Keywords: Red panda; Distribution; Status; Conservation; Habitat; Oxyuris

\section{INTRODUCTION}

Red Panda is an endemic and a flagship species in the Himalayan region (Roberts and Gittleman, 1984) which threatened with extinction worldwide (Wang et al., 2008). This species is an arboreal, shy, nocturnal and solitary in nature however sometime seen in a pair or group and travel a linear distance of $1.57 \mathrm{Km}$ during breeding season and active only in the late in the afternoon and/or early evening hours (Yonzon, 1989). The IUCN classifies the Red Panda as vulnerable status, suggesting a likely extinction globally if conservation measures are not initiated soon (Wang et al., 2008). On the basis of habitat suitability index,

Nepal is home to approximately $1.9 \%$ of total global population of Red Panda and $38 \%$ potential habitat of Red panda covered by Protected Areas where as remaining $62 \%$ by community managed and national forest (DNPWC/MoFSC/GoN, 2010). Currently, Red Pandas are believed to occur at low densities with a patchy distribution due to habitat fragmentation, loss of foraging habitat, human and livestock disturbances, poaching, and disease ( Patterson-Kane et al., 2009, Dorji et al., 2012, Sharma et al., 2014)

Parasitic infection is the one of disease in Panda (Zhang et al., 2006). Parasitic infection in animals as well as human negatively impact on body weight gain, quality of reproduction due to loss of appetite, nutrient uptake and utilization (Gross et al., 1999) even death in wild animals (Rao and Acharjyo, 1984, Hossain and Perry 1994). By using same grazing site by domestic and wild animals, there are chances of cross- transmission of parasites between wild to domestic or vice-versa (Hoberg and Brooks 2008, Agosta et al., 2010). A wide range of parasites have been identified that can infect both wild and domestic animals (Kock et al., 2002). The better understanding of cross- transmission help 
to makes management policy for both wild and domestic animals in different geographical area (Morgan et al., 2005). Historically, study of parasites in wild animals have been descriptive account (Thapa 2013, Chaudhary 2014 and Shrestha 2015) rather than clinical effect that the parasites cause i.e. morbidity and mortality.

\section{Materials AND Methods}

The study was carried out in Maimajhuwa, Mabu, Jamuna and Jogmai VDCs of Ilam, it was designed to include all the Red Panda and livestock which shared same land for grazing. From the GIS system study area was selected, for this elevation was $2200-4000 \mathrm{~m}$ and size of grids were $1.7 \times 1.7$ (2.89) $\mathrm{Km}^{2}$ while in each grid two transects were made. Fresh faecal Samples of both domestic animals as well as red Panda were collected from transects and opportunistically from the study area. Altogether 55 faecal samples were collected preserved in $2.5 \%$ Potassium dicromate. The entire faecal samples were examined in the laboratory of CDZ by both direct smear and concentration method for detection of intestinal parasites and intensity of parasites of Red Panda and livestock.

\section{RESUlts}

All the samples (Red Panda and livestocks) collected from study area were found positive for parasitic infection. Cyst, oocyst, eggs and larvae of different parasites were observed in both Red Panda and livestocks. During coprological examination three and seven genera of protozoan and nematode parasites were recorded in Red Panda while trematode and cestode were absent. Incase of livestock, three and six genera of protozoan and nematode parasites and one each genera of cestode and trematode were recorded. Eimeria sp. occyst showed the highly prevalent with $64.28 \%$ in Red Panda and $82.92 \%$ in Livestocks among protozoan paarasites while Oxyuris sp. egg showed the highest prevalent among nematode parasites with $100 \%$ and $87.8 \%$ in Red Panda and livestocks respectively. There was no statistical significant difference in prevalence of gastrointestinal parasites between Red Panda and livestocks ( $\mathrm{p}>0.05$ ). However, Entamoeba sp. showed the significant difference between them $(\mathrm{p}<0.05)($ Table 1$)$.

Table 1. Comparative analysis of GI parasites in between Red Panda and livestock

\begin{tabular}{|l|l|l|l|l|l|l|}
\hline S.N & Class & \multicolumn{1}{|c|}{ Parasites } & $\begin{array}{l}\text { Prevalence in } \\
\text { Red Panda }\end{array}$ & $\begin{array}{l}\text { Prevalence } \\
\text { in livestock }\end{array}$ & $\mathbf{X}^{2}$-Value & P-Value \\
\hline 1. & Sarcodina & Entamoeba sp. & $8(57.14 \%)$ & $9(21.95 \%)$ & 6.052 & 0.014 \\
\hline 2. & Sporozoa & $\begin{array}{l}\text { Eimeria with } \\
\text { micropyle }\end{array}$ & $9(64.28 \%)$ & $20(48.28 \%)$ & 1.007 & 0.316 \\
\cline { 3 - 7 } & $\begin{array}{l}\text { Eimeria without } \\
\text { micropyle }\end{array}$ & $8(57.14 \%)$ & $25(60.97 \%)$ & 0.064 & 0.800 \\
\hline 3. & Litostomatea & Balantidium sp. & $2(14.28 \%)$ & $3(7.31 \%)$ & 0.613 & $0.592^{*}$ \\
\hline 4. & Nematoda & Oxyuris sp. & $14(100 \%)$ & $36(87.8 \%)$ & 1.878 & $0.314^{*}$ \\
\hline 5. & & Strongyloid sp. & $7(50 \%)$ & $22(53.65 \%)$ & 0.056 & 0.813 \\
\hline 6. & & Hook worm & $5(35.7 \%)$ & $16(39.02 \%)$ & 0.048 & 0.826 \\
\hline 7. & & Trichostrongylus sp. & $7(50 \%)$ & $17(41.46 \%)$ & 0.309 & 0.578 \\
\hline 8. & & Crenosoma sp. & $6(42.85 \%)$ & 0 & 19.723 & $0.000^{*}$ \\
\hline 9. & & Ascaris sp. & $8(57.14 \%)$ & $25(60.975)$ & 0.064 & 0.800 \\
\hline 10. & & Trichuris $s p$. & $6(42.85 \%)$ & $7(31.70 \%)$ & 0.574 & 0.449 \\
\hline 11. & Cestode & Moniezia sp. & $0(0 \%)$ & $6(14.63 \%)$ & - & - \\
\hline 12. & Trematode & $\begin{array}{l}\text { Paramphiostomum } \\
\text { sp. }\end{array}$ & $0(0 \%)$ & $1(2.43 \%)$ & - & - \\
\hline
\end{tabular}

*= Fisher exact test accepted due to less than five expected value

From the analysis it showed that the transmission of parasites between Red Panda and livestock were possible. To know the parasites sharing groups with Red Panda livestocks were categories into cattle and goat/sheep. Morphologically similar parasitic egg/ cyst and larvae were compared.

There was no statistical significant difference in prevalence of gastrointestinal parasites in between Red Panda and Cattle and Red Panda and goat/ sheep ( $\mathrm{p}>0.05$ ) (Table: 2 and Table: 3 ). 
Cross Infection with Gastro-intestinal Tract Parasites between Red panda (Ailurus fulgens Cuvier, 1825) and Livestocks in Community Forest of Ilam, Nepal

Table 2. Prevalence of gastro-intestinal parasites in Red Panda and cattle

\begin{tabular}{|l|l|l|l|l|l|l|}
\hline S.N & Class & Parasites & $\begin{array}{l}\text { Prevalence in } \\
\text { Red Panda }\end{array}$ & $\begin{array}{l}\text { Prevalence } \\
\text { in cattle }\end{array}$ & $\mathbf{X}^{2}$-Value & P-value \\
\hline 1. & Sarcodina & Entamoeba sp. & $8(57.14 \%)$ & $7(53.84 \%)$ & 1.944 & 0.163 \\
\hline 2. & Sporozoa & $\begin{array}{l}\text { Eimeria with } \\
\text { micropyle }\end{array}$ & $9(64.28 \%)$ & $10(47.61 \%)$ & 0.940 & 0.332 \\
\cline { 3 - 7 } & & $\begin{array}{l}\text { Eimeria without } \\
\text { micropyle }\end{array}$ & $8(57.14 \%)$ & $13(61.53 \%)$ & 0.079 & 0.778 \\
\hline 3 & Litostimatidea & Balantidium sp. & $2(14.28 \%)$ & $2(9.52 \%)$ & 0.188 & $1.00^{*}$ \\
\hline 4 & Nematoda & Oxyuris sp. & $14(100 \%)$ & $19(90.47 \%)$ & 1.414 & $0.506^{*}$ \\
\hline 5 & & Strongyloid sp. & $7(50 \%)$ & $10(47.61 \%)$ & 0.019 & 0.890 \\
\hline 6. & & Hook worm & $5(35.7 \%)$ & $9(42.85 \%)$ & 0.179 & 0.673 \\
\hline 7 & & Trichostrongylus sp. & $7(50 \%)$ & $11(52.38 \%)$ & 0.19 & 0.778 \\
\hline 8. & & Ascaris sp. & $8(57.14 \%)$ & $12(57.14 \%)$ & 0.00 & 1.00 \\
\hline 9. & & Trichuris sp. & $7(42.85 \%)$ & $8(38.09 \%)$ & 0.079 & 0.778 \\
\hline 10. & & Crenosoma sp. & $6(42.85 \%)$ & 0 & 1.414 & $0.506^{*}$ \\
\hline
\end{tabular}

$*=$ Fisher exact test accepted due to less than five expected value

Table 3. Prevalence of gastro-intestinal parasites in Red Panda and goat/sheep

\begin{tabular}{|l|l|l|l|l|l|l|}
\hline S.N & Class & Parasites & $\begin{array}{l}\text { Prevalence in } \\
\text { Red Panda }\end{array}$ & $\begin{array}{l}\text { Prevalence } \\
\text { in Goat and } \\
\text { Sheep }\end{array}$ & $\mathbf{X}^{2}$-Value & P-value \\
\hline 1. & Sporozoa & $\begin{array}{l}\text { Eimeria with } \\
\text { micropyle }\end{array}$ & $8(57.14 \%)$ & $7(53.84 \%)$ & 0.304 & 0.581 \\
\cline { 2 - 7 } & & $\begin{array}{l}\text { Eimeria without } \\
\text { micropyle }\end{array}$ & $9(64.28 \%)$ & $8(61.53 \%$ & 0.054 & 0.581 \\
\hline 2 & Sarcodina & Entamoeba sp. & $8(57.14 \%)$ & 0 & 10.556 & $0.002^{*}$ \\
\hline 3 & Litostomatea & Balantidium sp. & $2(14.28 \%)$ & 0 & 2.006 & $0.481^{*}$ \\
\hline 4 & Nematoda & Oxyuris sp. & $14(100 \%)$ & $11(84.61 \%)$ & 2.326 & $0.222^{*}$ \\
\hline 5. & & Strongyloid sp. & $7(50 \%)$ & $8(61.53 \%)$ & 0.363 & 0.547 \\
\hline 6. & & Hook worm & $5(35.71 \%)$ & $5(38.46 \%)$ & 0.22 & 0.883 \\
\hline 7. & & Trichostronggylus sp. & $7(50 \%)$ & $6(46.15 \%)$ & 0.40 & 0.842 \\
\hline 8. & & Ascaris sp. & $8(57.14 \%)$ & $7(53.84 \%)$ & 0.30 & 0.863 \\
\hline 9. & & Trichuris sp. & $6(42.85 \%)$ & $5(38.46 \%)$ & 0.054 & 0.816 \\
\hline 10. & & Crenosoma sp. & $6(42.85 \%)$ & 0 & 7.163 & $0.016^{*}$ \\
\hline
\end{tabular}

$*=$ Fisher exact test accepted due to less than five expected value

\section{DisCUSSION AND CONCLUSION}

A total of 14 faecal samples of Red Panda and 41 samples of livestock were collected from the community forest of Ilam and examined by concentration methods. All the samples of both Red Panda and livestock were found to be positive either for protozoan or helminths. This prevalence rate of Red Panda was almost similar as compared to 93.02\% reported in Red panda from Rara National Park (RNP) (Shrestha et al., 2015) and 100\% in Kothi Bhir community area (KBCA), Rolpa (Lama et al.,2015). But higher than the reports of Bertelsen et al., (2010) and Pradhan et al., (2011) which showed 35\% and $46.66 \%$ parasitic infection from European zoo and Darjeeling, India respectively. The prevalence of gastrointestinal parasites of livestock in this study was similar with report of Bandyopadhyay et al., (2010) who reveal $92.4 \%$ prevalence rate in India and the prevalence was higher as compared to 81.82\%, 28.25\%, 66.29\% observed by Byanju et al., (2011), Laha et al., (2012) and shirale et al., (2009) respectively. High prevalence of parasites in Red panda and livestock clearly indicates that the parasites shared between them probably due to sharing the same pasture area.

From the economic and sanitary point of view, coccidian parasites are the most prevalent among protozoa. Coccidian parasite infects large number of wild animals including Red Panda and Raccoons. Eimeria is the most common Coccidian parasites among wildlife and livestock. The prevalence of Eimeria with micropyle and without micropyle in Ilam almost similar with Eimeria reported from RNP (Shrestha et al., 2015). High prevalence of Eimeria infection has been also reported from Raccoons of America (Dubey et al., 2000, Wright and Gompper 2005, Dubey 1982, Foster et al., 
2004, and Adams et al., 1981). Large number of livestock were also showen to be infected (Ntonifor et al., 2013, Kanyari et al., 2009, Swai et al., 2006, Biu et al., 2009). In the

present study, Eimeria was found to be $64.28 \%$ which was higher than $35 \%$ and $48 \%$ observed by Kanyari et al.,,(2009) in sheep and goat respectively, $17.8 \%$ by Laha et al., (2012) and $20.9 \%$ by Ntonifor et al., (2013) and lower than 85.7\% (Apio et al., 2013) and 76.5\% (Matsubayashi et al., 2009).

Almost similar prevalence of Eimeria in Red Panda and livestock may be due to the herbivorous food habitat of Red Panda sharing the same grazing area with livestock. Other Coccidian parasites such as Isospora sp., Cryptosporidium sp. and Cyclospora sp. have been reported from various other wild mammals including Raccoons (Taylor et al., 2007) and Red Panda (Lama et al., 2015). Isospora spp and Cryptosporidium spp are also absent in livestock.

Besides the Coccidian parasites, the Red Panda were found to be infected with two other protozoan parasites, Entamoeba sp. and Balantidium sp. Amoebic dysentery, an intestinal disease caused by infection with the protozoan parasite Entamoeba. spp. is an important disease of man and animals throughout the world. Entamoeba sp. had also been reported from Red Panda of RNP (Shrestha et al., 2015). In both RNP and Ilam, Red Panda were infected with more than 50\% by Entamoeba species. Entamoeba is causative agent of amoebiosis among livestock it has been reported from cattles of Kenya (Kanyari et al., 2009). In the present study, this parasite is also reported in cattle with prevalence rate $21.95 \%$ which was found to be less than $87 \%$ and $77 \%$ in Sheep and Goat by Kanyari et al., (2009) and 83\% by Paul et al., (2010) in cattle. The prevalence of Entamoeba in Red Panda was higher than livestock it was may be due to behavioral and genetic factors associated in Red Panda and livestock (Gillespie et al., 2005).

Balantidium coli is the ciliate zoonotics protozoan parasites. Non-human primates have been considered the most important reservoirs for human infection (Walzer and Healy 1982; Nakauchi, 1999). Balantidium sp. has been reported from White-handed gibbon (Hylobates lar), squirrel monkey (Saimiri sciurea), Japanese macaque (Macaca fuscata), wild boar (Sus scrofa) and chimpanzee (Pan troglodytes) from Japan (Nakauchi 1999). This is the first case to report the Balantidium sp. in Red Panda in the global context with prevalence rate $14.28 \%$. The prevalence of Balantidium $s p$. in livestock during the present study was lowest $(7.31 \%)$ than other protozoans which is similar to Kanyari et al., (2009) who reported $2 \%$ and 3\% prevalence in sheep and goat, $1.6 \%$ and $6.6 \%$ in cattle by Uysal et al .(2009) and Paul et al., (2010) respectively. B. coli was reported in pig by Ismail et al., (2010) and Weng et al., (2005) and observed 64.7\% and 47\% prevalence which was greater than prevalence of this study. The greater prevalence may be due to Many food or water resources can become polluted because pandas defecate while feeding (Zhang and Wei 2006).

The first report on isolation and maintenance of B. coli was done by Barrett and Yarbroug (1921) in animals. B. coli are a ciliated and a normal inhabitant of intestine of wild and domestic animals, probably capable of becoming somewhat pathogenic under favorable condition. It has been identified by Varadharajan and Kandasamy (2000) from India. The infection of $B$. coli may be due to the contamination of water or food with cyst in the grazing area (Schuster and Ramirez 2008).

Generally wild animals become infected with Nematode, Cestode and Trematode helminth parasites. To compared the life cycle of cestode and trematode, a suitable intermediate host is required but not for most of the nematode parasites. Interestingly, Red Panda of Ilam were found infected with only nematode parasites but livestock were infected by cestode and trematode too.

However the trematode, Ogmocotyle ailuri was previously described from Red Panda at a zoo in the America (Price 1954 and 1960). O. ailuri also isolated from the small intestine of Taiwanese monkey, Macaca cyclopis (Yoshimura et al.,1996) and Japanises monkey, Macaca fuscata (Iwaki et al., 2012).

Another trematode, Heterobiharzia americana also recorded in Archer and Wichita countries of north contra Texa and overall prevalence was $47.2 \%$ (Kelley 2010) and other trematodes Alaria sp, Digenea $s p$ and Eurytrema procyonis were observed in Raccoon (Wright and Gompper 2005). Prevalence of trematode were found 13\% in Red Panda from KBCA (Lama et al., 2015) but genera was unidentified. Absent of trematodes in present study might be due to absent of suitable intermediate 
host in Ilam. Trematode infection was most common among livestock (Bandyopadhaya et al.,, 2010, Yadav and Tando 1989, Byanju et al., 2011).

Cestode infection in Red Panda (Lama et al., 2015) had shown from KBCA similarly the Red Panda of RNP have been reported to be infected with Moniezia, a common herbivore cestode parasite but none of the Red Panda samples collected from Ilam were positive. However three genera of cestode had been reported from Raccoon in Archer and Wichita countries of North Central Taxas including Atrioenia procyonis, Mesocestoides spp., Taenia pisiformis (Kelley and Horner 2008). The cestode spp. described from cattle includes Moniezia (Horak et al., 2004, Kanyari et al., 2009, Laha et al., 2012) and Taenia (Biu et al., 2009). In the present study, only one cestode, Moniezia was recorded in cattle with prevalence rata $14 \%$ which was almost similar with $21 \%$ and $16 \%$ observed by Kanyari et al., (2009) in sheep and goat $10 \%$ and $11 \%$ infection reported by Laha et al.,, (2012) and Farooq et al.,, (2012) in cattle and higher than $0.65 \%$ and $0.48 \%$ revealed by Rafiullah et al., (2011) in male and female cattle respectively.

Altogether seven genera of nematodes in Red Panda and six genera of nematodes in livestock were observed from Ilam community forest. Among them Oxyuris sp. showed the 100\% prevalence rate in Red Panda which was highest than 58.14\% recorded by Shrestha et al., (2015). The highest prevalence rate of Oxyuris may be due to the cool climate of the area. Cool climate is suitable for the development of Oxyuris larva. The parasite was observed equally high prevalence $(87.8 \%)$ in livestock too.

Generally round worm of Red Panda are considered as Balyascaris but due to the indistinguishable shape and size, they are simply consider here as ascaris. Balyascaris is an important intestinal nematode of Red Panda as well as Raccoon. This parasite had been recorded from Spain in whiteheaded lemurs (Eulemur albifrons) (Martinez et al.,, 2015), North America (Kazacos, 2001) Germany (Bauer et al., 2011). In this study the prevalence of ascaris was found $57.14 \%$ which was higher than $38.88 \%$ and $13.04 \%$ prevalence rate of Balyascaris reported in Red Panda from Rara National Park, Mugu, Nepal (Shrestha et al.,2015) and Kothi Bhir Community area, Rolpa, Nepal (Lama et al.,2015) respectively. Balyascaris is found in Red Panda, Gient Panda, Raccoon, Cat, Dog etc. Nematodes like, B. procyonis, Capillaris acrophili, C. plica, C. procyonis, C. putorii and Placoconus lotoris had been reported in Raccoons from Southern New york (Wright and Gompper 2005). Similarly, $B$. procyonis was also reported in Raccoons from Western North Carolina (Hernandez et al., 2012). The highest prevalence rate were recorded from North-Eastern, mid-western ,mid-Atlantic, some western states (California, Washington, Oregon and Coloradol and some region of Taxas (Kazacos 2001, long et at. 2006, Chavez et al., 2012). In more than $85 \%$ of cases Infections have no symptoms, especially if the number of worms is small. During the study, the prevalence of Ascaris in livestock was $57.14 \%$ which agree with 57\% recorded by Awraris et al., (2012) in Ethiopia and greater than 1.5\%, 25.9\%, 17.6\%, 14.7\% and 3.7\% recorded by Chaoudhary et al., (1993), Tomass et al.,(2013), Ismail et al., (2010), Matsubayashi et al . (2009) and Uysal et al., (2009). Almost equal prevalence rate was observed in between Red Panda and livestock but it is indistinguishable between Ascaris found in Red Panda and livestock.

During the study, Trichostrongylus sp. was recorded for first time from Red Panda in the global context. The prevalence of Trichostrongylus sp. and Strongyloides sp. in Red Panda was found $41.46 \%$ and 50\% respectively. Strongyloides sp. had been recorded in Red Panda by Shrestha (2015) and prevalence was low compared to present study. The paraste was already recorded in American Raccoons from New york (Wright and Gompper 2005). In case of livestock, the parasite has been reported in Kenya (Kanyari et al., 2009), India (Laha et al., 2012), Pakistan (Rafiullah et al., 2011), Tanzania (swai et al.,, 2006) and Nigeria (Bui et al., 2009) with prevalence rate 13\%, 25.13\%, 4.21\%, $20 \%$ and $11 \%$ respectively. The prevalence rate of Strongyloides sp. was higher (53.65\%) as compare to all previous finding rate. The prevalence of Trichostrongylus sp. was found $41.46 \%$ which was higher than $13.83 \%$ and $16.24 \%$ infection recorded by Rafiullah et al., (2011) in male and female cattle respectively and lower than $55.8 \%$ recorded in goat and higher than $28.8 \%$ and $9.7 \%$ observed in sheep and cattle by Ntonifor et al., (2013). This result showed that Ilam community forest was highly contaminated with Strongyloides and Trichostongyloides eggs both from Red Panda and livestock. 
Trichuris is another common nematode parasite prevalent in both wild and domestic animals. The parasite has been reported from RNP (Shrestha 2015) and KBCA (lama et al., 2015). The prevalence of Trichuris was $42.85 \%$ which was higher than $4.65 \%$ and $26.08 \%$ recorded by Shrestha et al., (2015) and Lama et al., (2015) respectively. High worm load may cause growth retardation, anemia and hemorrhagic diarrhea (Hale and Stewart, 1979). Trichuris spp., have been infecting large number of livestock (Horak et al., 2004, Yadav and Tendon 1989, Byanju et al.,, 2011, Kanyari et al., 2009, Bui et al.,, 2009, Laha et al., 2012, Rafiullah et al., 2011). In the present study, Trichuris sp. (31.70\%) was isolated from cattle. The prevalence of Tichuris $s p$. was comparatively higher than $2 \%, 13.08 \%$, 5.27\%, 2.6\% recorded by Kanyari et al., (2009), Laha et al., (2012), Rafiullah et al., (2011) and Bui et al., (2009) respectively.

Crenosoma spp. is the Metastrongylus lungworm infecting wild and domesticated canids in Europe (Morgan et al., 2005, Traversa et al., 2010). Recently, emergence of this parasite was observed in several European countries (Traversa et al., 2010) due to population increase and urbanization of Red foxes (Vulpes vulpes) (Deplazes et al., 2004) which is the major reservoir hosts of this parasite in Europe. The prevalence of Crenosoma was found $42.85 \%$, in Red Panda which was almost similar 34.88\% by Shrestha et al., 2015 Rara National Park, Mugu, Nepal and higher than $4.3 \%$ from European zoos (Bertelsen et al.,2010). Hook Worm infection has been reported from Red Panda of RNP (Shrestha et al., 2015) with prevalence rate $44.19 \%$ which was almost similar with present study which revealed 35.7\%. Hookworms are cosmopolitan in distribution (Bowman et al.,, 2003) and can be transmitted orally but also by cutaneous penetration and cause high mortality in animals and human (Hotez et al., 2004). Crenosoma spp was not observed in cattle because it is the parasites of carnivore.

Angiostrongyloid vasorum was recorded in Red Panda from different countries. It is a most important lungworm which causes pathogenic pneumonia to Red Panda. A. vasorum was recorded from Denmark, U.K and European zoos by Bolt et al.,1992, Janet et al., 2009, Bertelsen et al., 2010 ) respectively. Angiostrongylus sp was also reported in Nepal (Lama et al., 2015 and Shrestha 2015) but during this study A. vasorum was not recorded. Aelurostrongyloid spp. have been reported in carnivora by different researchers in global and national context. In the present study, none of these nematodes were isolated in the faecal matter of Red Panda of Ilam community forest, Nepal. Some reports have been indicated the presence of Toxocara spp, Bunostomum spp, Haemonchus spp, Oesophagostomum spp, Cooperia spp, Ostertagia spp. etc from cattle (Hoorak et al., 2004, Bandyopadhyay et al., 2010, Bilal et al., 2009).

In conclusion, GIT parasites are major problems of animals in the study area. Therefore; comprehensive study on GIT parasites, cost effective strategic treatment and awareness creation to the farmers should be instituted and for the conservation of Red Panda grazing system of livestocks in the habitat of Red Panda should be stop to break the transmission processes.

\section{ACKNOWLEDGEMENTS}

We are greatly thankful to all the person who helped to complete this study and sincere thanks to

RHF for their financial support.

\section{REFERENCES}

[1] Adams, J.H., Levine, N.D., Todd, K.S. 1981. Eimeria and Ssarcocystis in raccoons in Illinois. Journal of Protozoology 28(2): 221-222.

[2] Agosta S.J., Janz N., Brooks D.R. 2010. How specialists can be generalists: resolving the "parasite paradox" and implications for emerging infectious disease. Zoologia, 27:151-162.

[3] Apio, A., Mohammed, O.B.Omer, S.A.2013. Cross infection with GIT parasites between goat and Farasan gazelle (Gazella gazelle farasani) in Farasan Islands, Saudi Arabia. Iournal of King Saud University science, 25: 325-329.

[4] Awraris, T., Bogale B. and Chanie , M. 2012. Occurrence of Gastro Intestinal Nematodes of Cattle in and Around Gondar Town, Amhara Regional State, Ethiopia. Acta Parasitologica Globalis 3 (2): 28-33,

[5] Bandyopadhyay, S., Pal P, Bhattacharya D, Bera AK, Pan D, Rahman H. (2010). A report on the prevalence of gastrointestinal parasites in yaks (Bos poephagus) in the cold desert area of North Sikkim, India. Trop Anim Health Prod, 42(1):119-21. 
Cross Infection with Gastro-intestinal Tract Parasites between Red panda (Ailurus fulgens Cuvier, 1825) and Livestocks in Community Forest of Ilam, Nepal

[6] Barrett, H.P. and Yarbrough, N. 1921. A method for the cultivation of Balan-tidium coli. Am. J. Trop. Med., 1: 161-165.

[7] Bauer, C. 2011. Baylisascariosis (Baylisascaris procyonis) - a rare parasitic zoonosis in Europe? Berl. Munch. Tierarztl. Wochenschr, 124 (11-12): 465-472

[8] Bertelsen, M.F., Meyland-Smith, F., Willesen, J.L., Jefferies, R., Morgan, E.R. and Monrad, J. 2010. Diversity and prevalence of metastrongyloid nematodes infecting the Red Panda (Ailurus fulgens) in European zoos. Veterinary Parasitology, 172: 299-304.

[9] Bertelsen, M.F., Meyland-Smith, F., Willesen, J.L., Jefferies, R., Morgan, E.R. and Monrad, J. 2010. Diversity and prevalence of metastrongyloid nematodes infecting the Red Panda (Ailurus fulgens) in European zoos. Veterinary Parasitology, 172: 299-304.

[10] Bilal, M.Q, Hameed, A. and Ahmad, T. 2009. Prevalence of gastrointestinal parasites in Buffalo and Cow calves in rural areas of Toba Tek Singh, Pakistan. The Journal of Animal \& Plant Sciences, 19(2): 67-70

[11] Biu A. A., Maimunatu, A. and Salamatu, A. F. 2009. A faecal survey of gastro intestinal parasites of ruminants on the University of Maiduguri Research Farm. International Journal of Biomedical and Health Sciences, 5(3): 115- 159.

[12] Bolt, G., Monrad, J., Henriksen, P., Dietz, H.H., Koch, J., Bindseil, E. and Jensen, A.L. 1992. The Fox (Vulpes vulpes) as a reservoir for canine angiostrongylosis in Denmark. Field survey and experimental infections. Acta Veterinaria Scandinavica, 33: 357-362.

[13] Bowman, D.D., Rock, T., Heaney, K., Neumann, N.R., Ulrich, M. and Amodie,D. 2003. Persistent efficacy of moxidectin canine sustained-releaseinjectable against experimental infections of Ancylostoma caninumand Uncinaria stenocephala in dogs. Vet. Ther., 4: 228-233.

[14] Byanju, R., Shrestha, S.P, Khanal, D.R. (2011). Prevalence of Gastrointestinal Parasites in Yaks of Lehe VDC, Manaslu Conservation Area. Nepal Journal of Science and Technology, 12: 366-369

[15] Carneri, I., 1972. Isolation of Balantidium coli in culture and study of thespeed of action of metronidazole and nitrimidazine. Rev. Inst. Med.Trop. São Paulo, 14: 321-325.

[16] Central Department of Statistics (CDS) 2002. Ministry of Population and Environment. HHMG Nepal.

[17] Chaudhary, R. B. 2014. Gastrointestinal parasites in Krisnasar (Antillope cervicapra) of Blackbuck conservation area, Bardiya and Suklaphanta Wildlif Reserve, Kanchanpur. M.sc. Thesis.Central Department of Zoology, Tribhuwan University, Kritipur, Kathmandu, Nepal.

[18] Chavez, D.J., LeVan, I.K., Miller, M.W. and Ballweber, L.R. 2012. Baylisascaris procyonis in raccoons (Procyon lotor) from eastern Colorado, an area of undefined prevalence. Veterinary Parasitology, 185: 330-334.

[19] Choudhury, A. 2001. An overview of the status and conservation of the Red Panda (Ailuru sfulgens) in India, with reference to its global status. Oryx, 35: 250-259.

[20] Deplazes, P., Hegglin, D., Gloor, S., Romig, T., 2004. Wilderness in the city :the urbanization of Echinococcus multilocularis. Trends Parasitol, 20: 77-84.

[21] DNPWC/MoFSC/GoN. 2010. Red Panda (Ailurus fulgens) Conservation Action Plan For Langtang National Park, Nepal. Government of Nepal, Ministry of Forests and Soil Conservation, Department of National Parks and Wildlife Conservation, Langtang National Park

[22] Dorji, S., Rajaratnam, R., Vernes, K. 2012. The Vulnerable red panda Ailurusfulgens in Bhutan: distribution, conservation status and management recommendations. Oryx, 46: 536-543.

[23] Dubey, J. P., Garner, M. M., Rosenthal, B. M. and DeGhetto, D. 2000. Clinical Coccidiosis in Raccoons (Procyon lotor). Journal of Parasitology, 86(6): 1299-1303.

[24] Dubey, J.P. 1982. Baylisascaris procyonis and eimerian infections in Raccoons. Journal of the American Veterinary Medical Association, 181(11): 1292- 1294.

[25] Farooq, Z., Mushtaq, S., Iqbal, Z., and Akhtar, S. 2012. Parasitic Helminths of Domesticated and Wild Ruminants in Cholistan Desert of Pakistan. International Journal of Agriculture and Biology, 14(1): 63-68

[26] Foster, G.W., McCleery, R.A. and Forrester, D.J. 2004. Intestinal Coccidia of Raccoons (Procyon lotor) from Key Largo, Florida, U.S.A. Comparative Parasitology, 71(2): 175-177

[27] Gillespie, T. R., E. C. Greiner, and C. A. Chapman. 2005. Gastrointestinal parasites of the colobus monkeys of Uganda. Journal of Parasitology, 91: 569-573.

[28] Gross, S.J., Ryan, W.G. and Ploeger, H.W. (1999), Anthelmintic treatment of adult dairy cows and the effect on milk production. Veterinary Journal, 144: In press

[29] Hale, O.M. and Stewart, T.B., 1979. Influence of an experimental infection of Trichuris suis on performance of pigs. J. Anim. Sci., 49: 1000-1005. 
Cross Infection with Gastro-intestinal Tract Parasites between Red panda (Ailurus fulgens Cuvier, 1825) and Livestocks in Community Forest of Ilam, Nepal

[30] Hernandez, S.M., Galbreath, B., Riddle, D.F., Moore, A.P., Palamar, M.B., and Levy, M.G. 2012. Baylisascaris procyonis in raccoons (Procyon lotor) from North Carolina and current status of the parasite in the USA. Parasitology Research, 112(2): 693-698.

[31] Hoberg E.P., Brooks D.R. 2008. A macroevolutionary mosaic: episodic host-switching, geographical colonization and diversification in complex host-parasite systems. J. Biogeogr, 35: 1533-1550.

[32] Horak I.G., Evans U., Purnell R.E. 2004. Parasites of domestic and wild animals in South Africa. XLV. Helminths of dairy calves on dry-land Kikuyu grass pastures in the Eastern Cape Province.Onderstepoort J. Vet. Res., 71: 291-306.

[33] Hossain, J., Perry, 1994. The epidemology, Diagnosis and Control of Helminth Parasites of Ruminants, 2nd ed., International Laboratory for Research on Animal Diseases (ILRAD).Nairobi, Kenya. pp. 80-92.

[34] Hossain, M.M., S. Paul, M.M. Rahman, F.M.A. Hossain, M.T. Hossain and M.R. Islam, 2011. Prevalence and economic significance of caprine fascioliasis at Sylhet district of Bangladesh. Pakistan Vet. J, 31: 113116

[35] Hossain, N. Md. 2012. Investigation on gastrointestinal parasites in captive wild animals and birds in Bangladesh Sheikh Mujjib Safari Park, Dulahazara, Cox's Bazar. M.sc. Thesis. Department of parasitology, Bangladesh Agricultural University, Mymensingh.

[36] Hotez, P.J., Brooker, S., Bethony, J.M., Bottazzi, M.E., Loukas, A., Xiao, S. 2004. Hookworm infection. N. Engl. J. Med., 351: 799-807.

[37] Ismail, H.A., Jeon, H.K, Yu ,Y.M .,Do, C., and Lee ,Y.H. 2010. Intestinal Parasite Infections in Pigs and Beef Cattle in Rural Areas of Chungcheongnam-do, Korea. Korean J Parasitol, 48(4): 347-349.

[38] Iwaki, T., Okada, T., Seki, K., Izawa, K. and Sakurai, F. 2012. Ogmocotyle ailuri (Price, 1954) (Digenea: Notocotylidae) Found in the Japanese Monkey, Macaca fuscata. Journal of Veterinary Medical Science, 74(9): 1211-1212.

[39] Janet, C. P.K., Lynda M.G., Jefferies, R., Morgan, E.R., Nanny, W. and Sharon P.R. 2009. Pneumonia from Angiostrongylus vasorum infection in a red panda (Ailurus fulgens fulgens). J Vet Diagn Invest, 21:270-273.

[40] Kanyari P W N, J M Kagira and R J Mhoma 2009. Prevalence and intensity of endoparasites in small ruminants kept by farmers in Kisumu Municipality, Kenya. Livestock Researcher for Rural Development vol. 21 (11).

[41] Kazacos, K.R. 2001. Baylisascaris procyonis and related species. In: Parasitic diseases of wild mammals. Samuels, W.M.; Pybus, M.J. and Kocans, A.A. (eds.). Iowa State University Press/Ames, Iowa. pp.: 301 341.

[42] Kelley, S.W. 2010. Heterobilharziasis (Trematoda: Schistosomatidae) in Raccoons (Procyon lotor) of north central Texas. The Texas Journal of Science 62(1).

[43] Kelley, S.W. and Horner, N.V. 2008. The prevalence of cestodes in raccoons (Procyon lotor) from north central Texas. Comparative Parasitology, 75: 292-298.

[44] Kock, R.A., Kebkiba, B., Heinonen, R., Bedane, B., 2002. Wildlife and pastoral society - shifting paradigms in disease control. Ann. NY Acad. Sci. 969, 24-33.

[45] Laha R., Das, M., Goswami, A. 2012. Gastrointestinal parasitic infections in organized cattle farms of Meghalaya. Vet. world., 2013: 109-112

[46] Lama, S.T., Lama, R.P., Regmi, G.R. and Ghimire, T.R. (2015). Prevalence of intestinal parasitic infections in free-ranging Red Panda Ailurus fulgens Cuvier, 1825 (Mammalia: Carnivora: Ailuridae) in Nepal. Journal of Threatened Taxa, 7(8): 7460-7464.

[47] Long, D.B., Campbell, T.A. and Henke, S.E. 2006. Baylisascaris procyonis (Nematoda: Ascaridoidea) in raccoon (Procyon lotor) from Duval County. Texas Journal of Sciences, 58(3): 281-285.

[48] Martinez, M.A.J, Cano, E.V, Rois, J.L. 2015. Baylisascaris procyonis larva migrans in two white-headed lemurs (Eulemur albifrons) in Spain and response to treatment derived from a human pediatric protocol. Veterinary Parasitology, 210: 246-249.

[49] Matsubayashi M, Kita T, Narushima T, Kimata I, Tani H, Sasai K, Baba E. 2009. Coprological survey of parasitic infections in pigs and cattle in slaughterhouse in Osaka, Japan. J Vet Med Sci., 71: 1079-1083

[50] Morgan, E.R., Shaw, S.E., Brennan, S.F., De Waal, T.D., Jones, B.R., Mulc-ahy, G., 2005. Angiostrongylus vasorum: a real heartbreakers. TrendsParasitol. 21: 49-51.

[51] Nakauchi, K. 1999. The Prevalence of Balantidium coli Infection in Fifty-Six Mammalian Species. J. Vet. Med. Sci., 61(1): 63-65. 
Cross Infection with Gastro-intestinal Tract Parasites between Red panda (Ailurus fulgens Cuvier, 1825) and Livestocks in Community Forest of Ilam, Nepal

[52] Ntonifor H. N., Shei S. J., Ndaleh N. W. and Mbunkur G. N. 2013. Epidemiological studies of gastrointestinal parasitic infections in ruminants in Jakiri, Bui Division, North West Region of Cameroon. Journal of Veterinary Medicine and Animal Health. Vol 5(12): 344- 352.

[53] Patterson-kane, J. C., Gibbons, L. M., Jefferies, R., Morgan, E. R., Wenzlow, N., Redrobe, S. P. 2009. Pneumonia from Angiostrongylus vasorum infection in a red panda (Ailurusfulgensfulgens). Journal of Veterinary Diagnostic Investigation, 21: 270-273.

[54] Paul, W.N.K., John, M.K., Jumanne, M.R.L. 2010. Prevalence of endoparasites in cattle within urban and peri-urban areas of Lake Victoria Basin, Kenya with special reference to zoonotic potential. Sci Parasitol, 11(4):171-178.

[55] Pradhan, S., Sharma, D., Subba, B. and Chettri, V. 2011. Preliminary investigation on the parasites of mammals at Padmaja Naidu Himalayan Zoological Park, Darjeeling. Zoo's PRINT, 26 (8): 11-13

[56] Price, E. W. 1960. A note on Ogmocotyle ailuri (Price, 1954) (Trematoda: Notocotylidae). Proceeding of the Helminthological Society of Washington 27: 119-121.

[57] Price, E.W. 1954. A new trematode from the lesser panda, Ailurus fulgens. Journal of Parasitology, 40: 3839.

[58] Rafiullah, A. A. T., Abdul S., Shah, S. R., Shabbir, A. and Muhammad, S. 2011. Prevalence of gastrointestinal tract parasites in cattle of Khyber Pakhtunkhwa ARPN Journal of Agricultural and Biological Science,.6: NO. 9,

[59] Rao, A.T and Acharjyo L.N. (1984). Diagnosis and classification of common diseases of captive animal at Nandan Kanan Zoo in Orissa (India). Indian J. Anim. Hlth.pp 147-152.

[60] Roberts, M. S., Gittleman, J. 1. 1984. Ailurusfulgens. Mammalian species, 222: 1-8.

[61] Sathaporn, J., Arkom, S., Burin N., Tawin, I., Chamnonjit, P. and Nongnuch, P. 2011. Prevalence of Gastro-Intestinal Parasites of Dairy Cows in Thailand. Kasetsart J. (Nat. Sci.) 45 : 40 - 45.

[62] Schuster, F.L., Ramirez. A. L., 2008. Current world status of Balantidiumcoli. Clin. Microbiol. Rev. 21: 626-638.

[63] Sharma, H. P., Belant, J. L., Swenson, J. E. 2014. Effects of livestock on occurrence of the Vulnerable red panda Ailurus fulgens in Rara National Park, Nepal. Oryx, 48: 228-231.

[64] Shirale, S.Y., Meshram, M.D., Khillare, K.P. (2009). Prevalence of gastrointestinal parasites in cattle of Western Vidarbha Region. Vet. World, 1:45

[65] Shrestha, C. K. 2015. Gastrointestinal parasites in Red Panda (Aelurus fulgens) of Rara National Park, Mugu, Rasuwa, Nepal. M.sc. Thesis Central Department of Zoology, Tribhuwan University, Kritipur, Kathmandu, Nepal.

[66] Swai, E. S., Mtui, P. F., Mbise, A. N., Kaaya, E., Sanka, P. and Loomu, P. M. 2006. Prevalence of gastro intestinal parasite infections in Maasai cattle in Ngorongoro District, Tanzania. Livestock research for rural development, 18 (8).

[67] Thapa, C. 2013. Prevalence of gastrointestinal parasites of Himalayan Tahr (Hemitragus jemlahicus) and Barking Deer (Muntiacus veginalis) of Rara National Park, M.sc. Thesis.Central Department of Zoology, Tribhuwan University, Kritipur, Kathmandu, Nepal.

[68] Tomass Z, Imam E, Kifleyohannes T , Tekle Y and Weldu.K. 2013. Prevalence of gastrointestinal parasites and Cryptosporidium species in extensively managed pigs in Mekelle and urban areas of southern zone of Tigray region, Northern Ethiopia vetworld.433-439

[69] Traversa, D., Di Cesare, A., Conboy, G., 2010. Canine and felinecardiopulmonary parasitic nematodes in Europe: emerging and underestimated. Parasit. Vectors, 3: 62.

[70] Uysal, H.K., Boral, O., Metiner, K. and Ilgaz, A. (2009) Investigation of intestinal parasites in pig feces that are also human pathogens. Turkiye Parazitol Derg., 33: 218-221.

[71] Varadharajan, A and Kandassamy, A. 2000. A survey of gastrointestinal parasites of wild animals in captivity in the V.O.C. Park and Mini Zoo, Coimbatore, India. . Zoos' print journal, 15(5): 257-258

[72] Walzer, P.D., Healy, G.R., 1982. Balantidiasis. In: Steele, J.H. (Ed.), Handbook Series in Zoonoses. CRC, Press, Inc., Boca Raton, FL, pp. 15-24.

[73] Wang, X., Choudhury, A., Yonzon, P. B., Wozencraft, C., Than,Z.(2008). Ailurusfulgens. In: IUCN 2012. IUCN Red List of Threatened Species. Version 2012.2. <www.iucnredlist.org>Downloaded on 7 April 2014.

[74] Weng, Y.B, Hu YJ, Li Y, Li BS, Lin RQ, Xie DH, Gasser RB, Zhu XQ. 2005. Survey of intestinal parasites in pigs from intensive farms in Guangdong Province, People's Republic of China. Vet Parasitol. 127: 333336. 
Cross Infection with Gastro-intestinal Tract Parasites between Red panda (Ailurus fulgens Cuvier, 1825) and Livestocks in Community Forest of Ilam, Nepal

[75] Weng, Y.B, Hu YJ, Li Y, Li BS, Lin RQ, Xie DH, Gasser RB, Zhu XQ. 2005. Survey of intestinal parasites in pigs from intensive farms in Guangdong Province, People's Republic of China. Vet Parasitol. 127: 333336.

[76] Wright, A.N. and Gompper, M.E. 2005. Altered parasite assemblages in raccoons in response to manipulated resource availability. Oecologia 144: 148-156.

[77] Wright, A.N. and Gompper, M.E. 2005. Altered parasite assemblages in raccoons in response to manipulated resource availability. Oecologia 144: 148-156.

[78] Yadav, A.K., Tandon,V., 1989.Gastrointestinal nematode infection of goat in a subtropical and humid zone of India.vet.Parasitol., 33(2): 135-142

[79] Yoshimura, K., Hishinuma, Y. and Sato, M. 1969. Ogmocotyle ailuri (Price, 1954) in the Taiwanese monkey, Macaca cyclopis (Swinhoe, 1862). Journal of Parasitology, 55: 460-461.

[80] Zhang, Z.H. and Wei, F.W. 2006. Giant Panda exsitu conservation theory and practice. Science Press, Beijing, China, 546 p.

Citation: S. Shrestha, M. Maharjan, "Cross Infection with Gastro-intestinal Tract Parasites between Red panda (Ailurus fulgens Cuvier, 1825) and Livestocks in Community Forest of Ilam, Nepal ", International Journal of Research Studies in Zoology, vol. 3, no. 4, p. 15-24, 2017. http://dx.doi.org/10.20431/2454941X.0304003

Copyright: (C) 2017 Authors. This is an open-access article distributed under the terms of the Creative Commons Attribution License, which permits unrestricted use, distribution, and reproduction in any medium, provided the original author and source are credited. 